\title{
Short-term outcomes of robot-assisted minimally invasive esophagectomy for esophageal cancer: a propensity score matched analysis
}

\author{
Haiqi He, Qifei Wu, Zhe Wang, Yong Zhang, Nanzheng Chen, Junke Fu and Guangjian Zhang*
}

\begin{abstract}
Background: Minimally invasive esophagectomy (MIE) was shown to be effective in reducing the morbidity and was adopted increasingly. The robot-assisted minimally invasive esophagectomy (RAMIE) remains in the initial stage of application. This study evaluated its safety and feasibility by comparing short-term outcomes of RAMIE and video-assisted minimally invasive esophagectomy (VAMIE).

Methods: Between March 2016 and December 2017, 115 consecutive patients underwent RAMIE or VAMIE at our institute. The baseline characteristics, pathological data and short-term outcomes of these two group patients were collected and compared. RAMIE patients were propensity score matched with VAMIE patients for a more accurate comparison.

Results: Matching based on propensity scores produced 27 patients in each group. After propensity score matching (PSM), the baseline characteristics between the two groups were comparable. The operation time in RAMIE group was significantly longer than that in VAMIE group (349 and 294 min, respectively; $P<0.001$ ). The blood loss volume in RAMIE group was less than that in VAMIE group (119 and $158 \mathrm{ml}$, respectively), but with no statistically significant difference $(P=0.062)$. There was no significant difference between the two groups with respect to the mean number of dissected lymph nodes (20 and 19, respectively; $P=0.420$ ), postoperative hospital stay (13.8 and 12.7 days, respectively; $P=0.548$ ), the rate of overall complications ( 37.0 and $33.3 \%$, respectively; $P=0.776$ ) and the rates of detailed complications between the two groups.
\end{abstract}

Conclusions: The short-term outcomes of RAMIE is comparable to VAMIE, demonstrating safety and feasibility of RAMIE.

Keywords: Esophageal cancer, Esophagectomy, Minimally invasive esophagectomy, Robot-assisted, Video-assisted

\section{Background}

Esophageal cancer is one of the most commonly diagnosed cancers around the world. At present, esophageal cancer is the sixth and ninth leading causes of cancerrelated mortality among men and women, respectively [1]. In China, it is estimated that there are approximately 477,900 new esophageal cancer cases and 375,000 deaths in 2015 [2]. For esophageal cancer, surgical resection with radical lymphadenectomy remains a critical element in the multimodality management [3], and transthoracic

\footnotetext{
* Correspondence: michael8039@163.com

Department of thoracic surgery, The First Affiliated Hospital of Xi'an Jiaotong University, 277 West Yanta Road, Xi'an, Shaanxi 710061, China
}

esophagectomy is the preferred surgical procedure worldwide, which is conducive to en bloc resection of the tumor along with the mediastinal lymph nodes [4]. However, the open transthoracic approach is associated with high rates of postoperative complications due to the surgical trauma [5]. Therefore, to reduce the morbidity as a result of surgical trauma from open procedures, minimally invasive esophagectomy (MIE) was adopted. The role of MIE has been well established in the last few years [6-9]. Nevertheless, the MIE is not routinely applied worldwide for its high technical complexity and steep learning curve [10].

As an alternative, robotic surgery may provide the minimally invasive option for more surgeons and

(c) The Author(s). 2018 Open Access This article is distributed under the terms of the Creative Commons Attribution 4.0 International License (http://creativecommons.org/licenses/by/4.0/), which permits unrestricted use, distribution, and 
patients, because the robotic platform provides improved visualization with a magnified three-dimensional view and improved articulation of instruments with seven degrees of freedom, and thereby allows for precise manipulation and dissection. Although the robotassisted esophagectomy was completed as early as 2003 $[11,12]$, it remains in the initial stage of application [13]. At present, there were few reports comparing RAMIE with VAMIE.

Thus, the aim of this study was to determine the safety and feasibility by comparing the short-term outcomes between RAMIE and VAMIE in patients with esophageal cancer.

\section{Methods}

\section{Patient selection}

We retrospectively reviewed the medical records of consecutive 115 patients who underwent McKeown minimally invasive esophagectomy in our institution for esophageal cancer without any previous neoadjuvant therapy from March 2016 to December 2017. Preoperatively, all patients underwent upper gastrointestinal endoscopy, contrast-enhanced computed tomography (CT) scan of the chest and upper abdomen, pulmonary function routinely, and were evaluated as resectable esophageal cancer. This study was approved by the ethics committee of Xi'an Jiaotong University. Each patient gave consent before the operation.

\section{Operation method}

All patients underwent RAMIE or VAMIE with twofield lymph node dissection. RAMIE was completed using da Vinci surgical system (Intuitive Surgical, Inc., Sunnyvale, CA, USA). All patients were intubated with a double-lumen tube. During the thoracic phase, the patients were placed in the left lateral decubitus position. The trocars for thoracic part of RAMIE were placed as shown in Fig. 1a. An 8-mm robotic trocar was placed in the 3rd or 4th intercostal space (ICS) on the anterior axillary line, and another 8 - $\mathrm{mm}$ robotic trocar
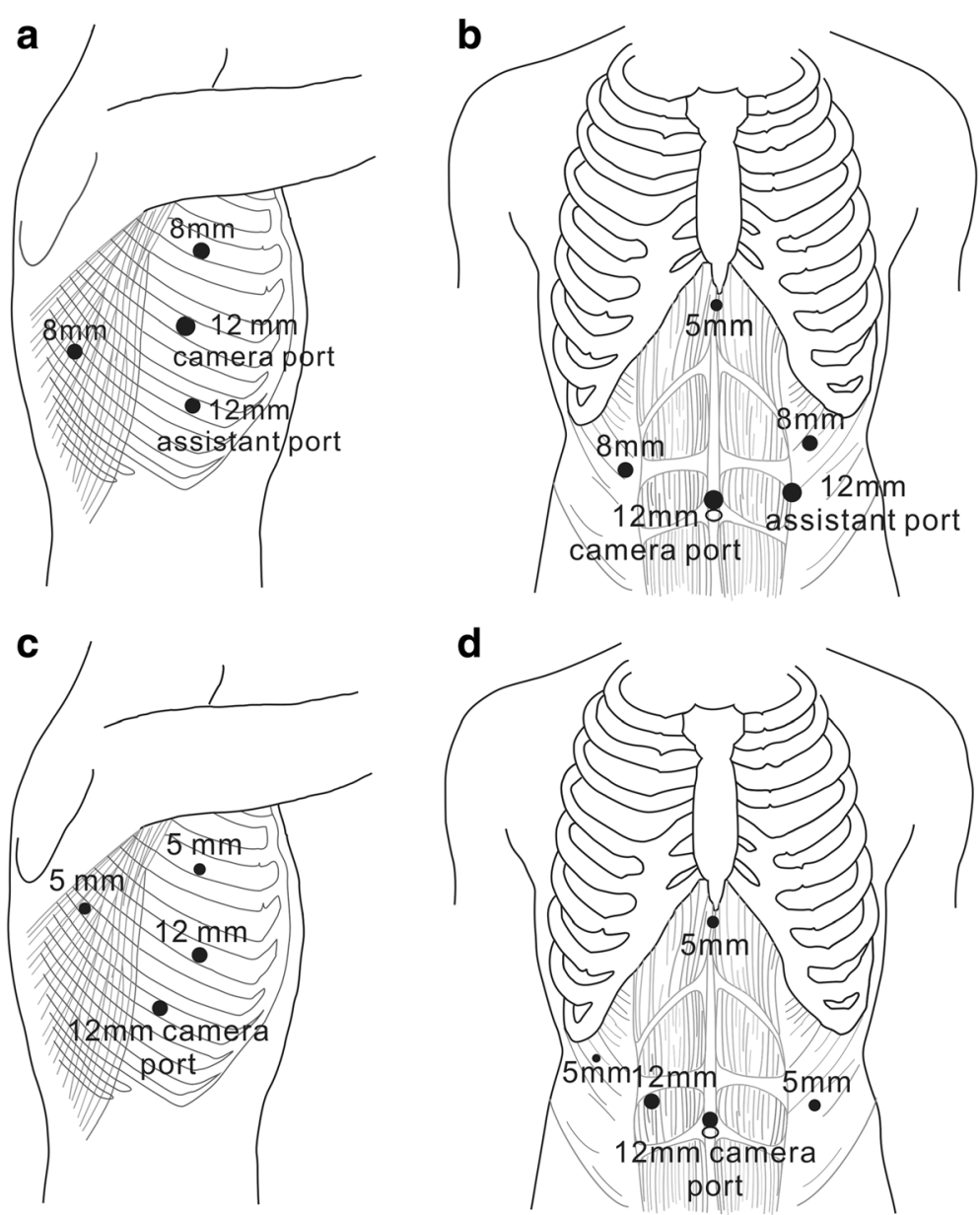

Fig. 1 Trocar placement for thoracic part (a) and abdominal part (b) of robot-assisted minimally invasive esophagectomy, and for thoracic part (c) and abdominal part (d) of video-assisted minimally invasive esophagectomy 
was placed in the 8th ICS between the posterior axillary line to scapular line. A 12-mm camera trocar was placed in the 5th or 6th ICS on the middle axillary line. A 12$\mathrm{mm}$ assistant trocar was placed in the 7th ICS on the anterior axillary line. The trocars for thoracic part of VAMIE were placed as follows: a $5-\mathrm{mm}$ and a $12-\mathrm{mm}$ working trocar were placed in the 4th and 6th ICS on the anterior axillary line, respectively; a $12-\mathrm{mm}$ camera trocar was placed in the 7th ICS on the middle axillary line; a 5-mm assistant trocar was placed in the 6th ICS between the posterior axillary line to scapular line. Insufflation with $\mathrm{CO}_{2}$ at a pressure of 7-10 $\mathrm{mmHg}$ was used for both RAMIE and VAMIE during thoracic part. The esophagus was mobilized along with all periesophageal lymph nodes. The azygous vein was routinely ligated with Hem-o-lock clips and divided. The lymph nodes along bilateral recurrent laryngeal nerve were dissected carefully.

Trocar placement for abdominal part of RAMIE and VAMIE were shown in Fig. 1b and d. A 5-mm trocar under the xiphoid process was used in both RAMIE and VAMIE to retract the liver. When the mobilized stomach was taken out through the upper abdominal small incision, a 4-cm-wide gastric conduit was constructed with the linear tissue staplers. Then the gastric tube was pulled up to the neck through the mediastinum and a cervical end-to-side anastomosis was performed with a circular stapler.

\section{Data collection}

The baseline characteristics, pathological data and shortterm outcomes were retrospectively collected, including gender, age, body mass index (BMI), Charlson comorbidity index, forced expiratory volume in $1 \mathrm{~s}$ (FEV1\%), tumor location, tumor grade, operation time, blood loss, the number of retrieved lymph nodes, pathological stage, postoperative hospital stay and postoperative complications. All patients were staged using the American Joint Committee on Cancer (AJCC) 7th edition TNM staging system. The postoperative complications were diagnosed and categorized based on clinical symptoms, combined with laboratory tests and radiological imaging findings. Pulmonary complications were defined as pneumonia, atelectasis requiring sputum suction bronchoscopy, acute respiratory failure, acute respiratory distress syndrome (ARDS). Recurrent laryngeal nerve injury was diagnosed at any sign of voice change or aspiration. The diagnosis of anastomotic leakage was based on definite clinical features, confirmed by esophagography and gastroscopy. Other complications were also recorded, including chylothorax, delayed gastric emptying, hemorrhage, pleural effusion and wound infection. Postoperative death was defined as death within 90 days after surgery.

\section{Statistical analysis}

SPSS software version 22.0 was used for statistical analysis. In order to overcome the data heterogeneity, the RAMIE cases were propensity scored matched to VAMIE cases according to gender, age, BMI, Charlson comorbidity index, forced expiratory volume in $1 \mathrm{~s}$ (FEV1\%), tumor location, pathologic T stage, and pathologic $\mathrm{N}$ stage. The operation time, blood loss, the number of dissected lymph nodes and postoperative complications were compared between the RAMIE and the VAMIE groups. Data were expressed as the mean \pm standard deviation for continuous variables or number (\%) for categorical data. Continuous variables were analyzed using Student's test or Mann-Whitney U test, depending on normality of distribution; while categorical data were analyzed using chi-square or Fisher's exact test. $P<0.05$ was considered statistically significant.

\section{Results}

A total of 115 patients with esophageal cancer met the inclusion criteria between March 2016 and December 2017. Twenty-seven patients underwent RAMIE, and 88 patients received VAMIE. The baseline characteristics were shown in Table 1 . There were significant differences between the two groups in FEV1\% predicted and pathologic $\mathrm{T}$ stage. The average pulmonary function represented by FEV1\% predicted was higher in RAMIE group than VAMIE group $(P=0.012)$. Patients in the VAMIE group presented more frequently with advanced $\mathrm{T}$ stage $(P=0.042)$. Other characteristics were similar between the two groups.

The operation time in RAMIE group was significantly longer than that in VAMIE group (349 and $294 \mathrm{~min}$, respectively; $P<0.001)$. However, the blood loss in RAMIE was less than that in VAMIE group (118 and $165 \mathrm{ml}$, respectively; $P=0.030$ ). The mean number of dissected lymph nodes in RAMIE group was similar to that in VAMIE group (20 and 18, respectively; $P=0.214$ ). Within 90 days after surgery, there were two patients died in VAMIE group; whereas there was no patient died in RAMIE group $(P=1.000)$. There were no differences between the two groups with respect to postoperative hospital stay (13.8 and 14.1 days, respectively; $P=0.548$ ) as well as the rates of overall postoperative complications (37.0 and $42.0 \%$, respectively; $P=0.643$ ) and detailed complications (Table 2).

To reduce the bias arising from baseline characteristics such as FEV1\% predicted and pathologic T stage, a 1:1 propensity score matching analysis was performed. Propensity score matching analysis produced 27 patients in each group. After PSM, patient characteristics were well balanced between the two matched groups (Table 1). The operation time was still significantly longer in RAMIE group (349 and $285 \mathrm{~min}$, respectively; $P<0.001$ ). Although 
Table 1 Patients' characteristics before and after propensity score matching

\begin{tabular}{|c|c|c|c|c|c|c|}
\hline \multirow[t]{2}{*}{ Variables } & \multicolumn{3}{|l|}{ Before matching } & \multicolumn{3}{|l|}{ After matching } \\
\hline & RAMIE $(n=27)$ & VAMIE $(n=88)$ & $P$ value & RAMIE $(n=27)$ & VAMIE $(n=27)$ & $P$ value \\
\hline Gender & & & 0.636 & & & 1.000 \\
\hline Male & $20(74.1)$ & $61(69.3)$ & & $20(74.1)$ & $20(74.1)$ & \\
\hline Female & $7(25.9)$ & $27(30.7)$ & & $7(25.9)$ & $7(25.9)$ & \\
\hline Age & $61.0 \pm 8.0$ & $62.9 \pm 8.3$ & 0.310 & $61.0 \pm 8.0$ & $61.6 \pm 9.8$ & $0.621^{*}$ \\
\hline $\mathrm{BMI}\left(\mathrm{kg} / \mathrm{m}^{2}\right)$ & $21.5 \pm 2.7$ & $21.4 \pm 2.7$ & 0.935 & $21.5 \pm 2.7$ & $21.9 \pm 2.8$ & 0.578 \\
\hline FEV1\% predicted & $94.5 \pm 13.8$ & $84.2 \pm 19.6$ & 0.012 & $94.6 \pm 13.8$ & $92.9 \pm 23.0$ & 0.747 \\
\hline Charlson comorbidity index & & & 0.198 & & & 0.506 \\
\hline 1 & $1(3.7)$ & $6(6.8)$ & & $1(3.7)$ & $4(14.8)$ & \\
\hline 2 & $10(37.0)$ & $20(22.7)$ & & $10(37.0)$ & $8(29.6)$ & \\
\hline 3 & $13(48.1)$ & $37(42.0)$ & & $13(48.1)$ & $11(40.7)$ & \\
\hline 4 & $3(11.1)$ & $25(28.4)$ & & $3(11.1)$ & $4(14.8)$ & \\
\hline Tumor location & & & 0.457 & & & 0.514 \\
\hline Proximal & $1(3.7)$ & $8(9.1)$ & & $1(3.7)$ & $3(11.1)$ & \\
\hline Middle & $18(66.6)$ & $48(54.5)$ & & $18(66.6)$ & $15(55.6)$ & \\
\hline Distal/EGJ & $8(29.6)$ & $32(36.4)$ & & $8(29.6)$ & $9(33.3)$ & \\
\hline Histological type & & & 0.395 & & & $0.334 \dagger$ \\
\hline Squamous cell carcinoma & $23(85.2)$ & $80(90.9)$ & & $23(85.2)$ & 25 (92.6) & \\
\hline other & $4(14.8)$ & $8(9.1)$ & & $4(14.8)$ & $2(7.4)$ & \\
\hline Pathologic T stage & & & 0.042 & & & 0.334 \\
\hline $\mathrm{T} 1$ & $4(14.8)$ & $13(14.8)$ & & $4(14.8)$ & $1(3.7)$ & \\
\hline $\mathrm{T} 2$ & $13(48.1)$ & $21(23.9)$ & & $13(48.1)$ & $13(48.1)$ & \\
\hline $\mathrm{T} 3$ & $10(37.0)$ & $54(61.4)$ & & $10(37.0)$ & $13(48.1)$ & \\
\hline Pathologic N stage & & & 0.260 & & & 0.387 \\
\hline NO & $13(48.1)$ & $58(65.9)$ & & $13(48.1)$ & $18(66.6)$ & \\
\hline N1 & $10(37.0)$ & $17(19.3)$ & & $10(37.0)$ & $8(29.6)$ & \\
\hline N2 & $3(11.1)$ & $11(12.5)$ & & $3(11.1)$ & $1(3.7)$ & \\
\hline N3 & $1(3.7)$ & $2(2.3)$ & & $1(3.7)$ & 0 & \\
\hline Tumor grade & & & 0.399 & & & 0.285 \\
\hline Well differentiated & $2(7.4)$ & $13(14.8)$ & & $2(7.4)$ & $6(22.2)$ & \\
\hline Moderate differentiated & 19 (70.4) & $63(71.6)$ & & 19 (70.4) & $17(63.0)$ & \\
\hline Poorly differentiated & $6(22.2)$ & 12 (13.6) & & $6(22.2)$ & $4(14.8)$ & \\
\hline
\end{tabular}

Data were presented as mean \pm standard deviation for continuous variables or number (\%) for categorical data

*Mann-Whitney $\mathrm{U}$ test; + Fisher's exact test

RAMIE robot-assisted minimally invasive esophagectomy, VAMIE video-assisted minimally invasive esophagectomy, BMI Body mass index, FEV1 forced expiratory volume in $1 \mathrm{~s}$, GEJ gastroesophageal junction

the mean blood loss volume in RAMIE group was still less than that in VAMIE group, this difference was no longer statistically significant (119 and $158 \mathrm{ml}$, respectively; $P=0.062$ ). There was no significant difference between the two groups with respect to the mean number of dissected lymph nodes (20 and 19 , respectively; $P=0.420$ ), postoperative hospital stay (13.8 and 12.8 days, respectively; $P=0.128$ ) as well as the rates of overall postoperative complications (37.0 and 33.3\%, respectively; $P=0.776)$ and detailed complications.

\section{Discussion}

In the recent years, multiple reports have demonstrated that MIE could decrease blood loss, the length of stay, and surgical complications [6-9]. This encourages the surgeon to use and develop the minimally invasive techniques. As a novel minimally invasive technique, the robot-assisted approach has been successfully used for esophagectomy. However, the safety and feasibility of RAMIE have not been completely determined. Therefore, the present study compared the short-term outcomes of 
Table 2 Postoperative outcomes of propensity score-unmatched and matched patients

\begin{tabular}{|c|c|c|c|c|c|c|}
\hline \multirow[t]{2}{*}{ Postoperative outcomes } & \multicolumn{3}{|c|}{ Before matching } & \multicolumn{3}{|l|}{ After matching } \\
\hline & RAMIE $(n=27)$ & VAMIE $(n=88)$ & $P$ value & RAMIE $(n=27)$ & VAMIE $(n=27)$ & $P$ value \\
\hline Operation time (minutes) & $349 \pm 45$ & $294 \pm 52$ & $<0.001$ & $349 \pm 45$ & $285 \pm 66$ & $<0.001$ \\
\hline Blood loss (mL) & $118 \pm 71$ & $165 \pm 107$ & $0.030^{*}$ & $119 \pm 72$ & $158 \pm 82$ & $0.062^{*}$ \\
\hline Number of harvested LNs & $20 \pm 7$ & $18 \pm 6$ & $0.214^{*}$ & $20 \pm 7$ & $19 \pm 5$ & $0.420^{*}$ \\
\hline Postoperative hospital stay (day) & $13.8 \pm 2.0$ & $14.1 \pm 4.2$ & $0.548^{*}$ & $13.8 \pm 2.0$ & $12.8 \pm 2.7$ & 0.128 \\
\hline Overall complication (at least one) [n (\%)] & $10(37.0)$ & $37(42.0)$ & 0.643 & $10(37.0)$ & $9(33.3)$ & 0.776 \\
\hline RLN injury [n (\%)] & $4(14.8)$ & $14(15.9)$ & 0.891 & $4(14.8)$ & $3(11.1)$ & $1.000+$ \\
\hline Pulmonary complication [n (\%)] & $5(18.5)$ & $16(18.2)$ & 0.968 & $5(18.5)$ & $2(7.4)$ & 0.224 \\
\hline Arrhythmia [n (\%)] & $1(3.7)$ & $8(9.1)$ & 0.362 & $1(3.7)$ & 0 & $1.000+$ \\
\hline Anastomotic leak [n (\%)] & $3(11.1)$ & $9(10.2)$ & 0.763 & $3(11.1)$ & $1(3.7)$ & $0.351 \dagger$ \\
\hline Chylothorax [n (\%)] & 0 & $1(1.1)$ & $1.000+$ & 0 & $1(3.7)$ & $1.000+$ \\
\hline Bleeding [n (\%)] & $1(3.7)$ & $2(2.3)$ & $0.556+$ & $1(3.7)$ & $1(3.7)$ & $1.000+$ \\
\hline Delayed gastric emptying [n (\%)] & $1(3.7)$ & $7(8.0)$ & 0.448 & $1(3.7)$ & 0 & $1.000+$ \\
\hline 90-day mortality [n (\%)] & 0 & $2(2.3)$ & $1.000+$ & 0 & $1(3.7)$ & $1.000+$ \\
\hline
\end{tabular}

Data were presented as mean \pm standard deviation for continuous variables or number (\%) for categorical data

*Mann-Whitney $U$ test; †Fisher's exact test

RAMIE robot-assisted minimally invasive esophagectomy, VAMIE video-assisted minimally invasive esophagectomy, RLN recurrent laryngeal nerve

RAMIE with that of VAMIE. We found that there were no significant differences in blood loss, the number of dissected lymph nodes, postoperative hospital stay, and rates of postoperative complications, although RAMIE took longer operation time than VAMIE, mainly attributing to the docking and undocking. These results suggested that RAMIE is a safe and feasible technique, comparable to VAMIE.

Because of the high technical complexity and steep learning curve, the conventional VAMIE is not routinely applied worldwide [10]. Theoretically, the magnified three-dimensional view combined with seven degrees of freedom of the articulating surgical instruments facilitates meticulous dissection and thereby can accelerate the learning curve of RAMIE and decrease the operation time [14]. Narula et al. [15] evaluated technical enhancement of robotic and laparoscopic instrumentation in the task performance, using a computerized assessment system, and they found that the tasks were performed faster and more precisely with the robotic technology than standard laparoscopy. Further study by Chandra et al. [16] compared robotic and laparoscopic-assisted suturing performance for experts and novices. For laparoscopic novices, robotic technology significantly improves performance and accuracy. For laparoscopic experts, robotic technology significantly decreases the total instrument path length. Therefore, the robot is particularly useful for performing precise dissection in limited spaces, such as the mediastinal lymphadenectomy.

Actually, the advantages of RAMIE over VAMIE have not been well confirmed so far, even though RAMIE was completed as early as 2003 [11, 12]. During the past decade, several groups have reported their results describing the safety and feasibility of the technique [13, 17-23]. Weksler et al., [24] compared 11 patients who underwent RAMIE and 26 patients who underwent VAMIE. They found that RAMIE was equivalent to VAMIE in terms of operation time, blood loss, the number of dissected lymph nodes, postoperative complications and length of stay. Yerokun et al. [7] reached the same conclusion by comparing the short-term outcomes of 117 cases with RAMIE and 117 cases with VAMIE. In terms of postoperative complications, most previous studies [24-27] together with our present study suggested that the rates of complications were comparable between RAMIE and VAMIE, although a higher rate of anastomotic leakage was found in the RAMIE in the study by Suda et al. [28].

The lymphadenectomy is a key step in radical esophagectomy for esophageal cancer. Lymph node dissection along bilateral recurrent laryngeal nerves (RLN) has always been a challenge in MIE due to frequent recurrent laryngeal nerve injury. The robotassisted lymphadenectomy along bilateral RLNs was demonstrated to be technically feasible and safe [29]. The study by Park et al. [25] included 62 RAMIE and 43 VAMIE. They found that RAMIE yielded more number of dissected lymph nodes than VAMIE. The same conclusion was drawn by Deng et al. [27] in a recent study, which included 42 patients in both RAMIE and VAMIE groups. Suda et al. [28] showed that RAMIE reduced the incidence of RLN injury, although it did not increase the number of harvest lymph nodes. Chao et al. [26] found that RAMIE 
yielded more lymph nodes along the left RLN than VAMIE. However, other previous studies [7, 24] together with our study suggested that the number of dissected lymph nodes of RAMIE was comparable to that of VAMIE. These results varied from series to series may be due to their different experience.

Anyway, this study combined with previous studies suggested that RAMIE is a safe and feasible technique, and its efficacy is comparable to VAMIE in terms of short-term outcomes. However, the limitation of our study is that it has a small sample size and it is a nonrandomized controlled study. At present, there aren't large-scale studies comparing these two minimally invasive technologies for esophagectomy. Interestingly, an ongoing randomized controlled trial by van der Sluis et al. [30] are now comparing robot-assisted with conventional open transthoracic esophagectomy. The result of ROBOT trial will provide more conclusive data.

\section{Conclusions}

RAMIE is technically safe and feasible. The short-term outcomes of RAMIE are comparable to VAMIE. The advantages of robotic system may allow precise dissection of lymph nodes in the mediastinum and help us to decrease blood loss.

\section{Abbreviations}

BMI: Body mass index; CT: Computed tomography; FEV1: Forced expiratory volume in $1 \mathrm{~s}$; GEJ: Gastroesophageal junction; ICS: Intercostal space; MIE: Minimally invasive esophagectomy; PSM: Propensity score matching; RAMIE: Robot-assisted minimally invasive esophagectomy; RLN: Recurrent laryngeal nerve; VAMIE: Video-assisted minimally invasive esophagectomy

\section{Availability of data and materials}

The data supporting the conclusions of this article are included in the article.

\section{Authors' contributions}

$\mathrm{HH}$ collected the data, wrote the manuscript. QW and NC collected and analyzed the data. GZ carried out the study design, made the main correction and participate in surgery. JF performed the surgeries and approved the final manuscript. YZ and ZW participate in surgery. All authors read and approved the final manuscript

\section{Ethics approval and consent to participate}

Ethics approval for this study was obtained from approved by the ethics committee of Xi'an Jiaotong University.

\section{Consent for publication}

The patients included in the study provided their informed consent.

\section{Competing interests}

The authors declare that they have no competing interests.

\section{Publisher's Note}

Springer Nature remains neutral with regard to jurisdictional claims in published maps and institutional affiliations.

Received: 9 November 2017 Accepted: 9 May 2018

Published online: 23 May 2018

\section{References}

1. Torre LA, Bray F, Siegel RL, Ferlay J, Lortet-Tieulent J, Jemal A. Global cancer statistics, 2012. CA Cancer J Clin. 2015;65(2):87-108.
2. Chen W, Zheng R, Baade PD, Zhang S, Zeng H, Bray F, Jemal A, Yu XQ, He J. Cancer statistics in China, 2015. CA Cancer J Clin. 2016;66(2):115-32.

3. Mariette C, Piessen G, Triboulet JP. Therapeutic strategies in oesophageal carcinoma: role of surgery and other modalities. Lancet Oncol. 2007;8(6): 545-53.

4. Boone J, Livestro DP, Elias SG, Borel Rinkes IH, van Hillegersberg R. International survey on esophageal cancer: part I surgical techniques. Dis Esophagus. 2009;22(3):195-202.

5. Hulscher JB, van Sandick JW, de Boer AG, Wijnhoven BP, Tijssen JG, Fockens P, Stalmeier PF, ten Kate FJ, van Dekken H, Obertop H, et al. Extended transthoracic resection compared with limited transhiatal resection for adenocarcinoma of the esophagus. New Engl J Med. 2002;347(21):1662-9.

6. Biere SS, van Berge Henegouwen MI, Maas KW, Bonavina L, Rosman C, Garcia JR, Gisbertz SS, Klinkenbijl JH, Hollmann MW, de Lange ES, et al. Minimally invasive versus open oesophagectomy for patients with oesophageal cancer: a multicentre, open-label, randomised controlled trial. Lancet. 2012:379(9829):1887-92.

7. Yerokun BA, Sun Z, Jeffrey Yang CF, Gulack BC, Speicher PJ, Adam MA, D'Amico TA, Onaitis MW, Harpole DH, Berry MF, et al. Minimally invasive versus open Esophagectomy for esophageal Cancer: a population-based analysis. Ann Thorac Surg. 2016:102(2):416-23.

8. Luketich JD, Pennathur A, Awais O, Levy RM, Keeley S, Shende M, Christie NA, Weksler B, Landreneau RJ, Abbas G, et al. Outcomes after minimally invasive esophagectomy: review of over 1000 patients. Ann Surg. 2012; 256(1):95-103.

9. Zhou C, Zhang L, Wang H, Ma X, Shi B, Chen W, He J, Wang K, Liu P, Ren Y. Superiority of minimally invasive Oesophagectomy in reducing in-hospital mortality of patients with Resectable Oesophageal Cancer: a meta-analysis. PLoS One. 2015;10(7):e0132889.

10. Mamidanna R, Bottle A, Aylin P, Faiz O, Hanna GB. Short-term outcomes following open versus minimally invasive esophagectomy for cancer in England: a population-based national study. Ann Surg. 2012;255(2):197-203.

11. van Hillegersberg R, Boone J, Draaisma WA, Broeders IA, Giezeman MJ, Borel Rinkes $\mathrm{IH}$. First experience with robot-assisted thoracoscopic esophagolymphadenectomy for esophageal cancer. Surg Endosc. 2006; 20(9):1435-9.

12. Kernstine KH, DeArmond DT, Karimi M, Van Natta TL, Campos JH, Yoder MR, Everett JE. The robotic, 2-stage, 3-field esophagolymphadenectomy. J Thorac Cardiovasc Surg. 2004;127(6):1847-9.

13. Ruurda JP, van der Sluis PC, van der Horst S, van Hilllegersberg R. Robotassisted minimally invasive esophagectomy for esophageal cancer: a systematic review. J Surg Oncol. 2015;112(3):257-65.

14. Finley DS, Nguyen NT. Surgical robotics. Curr Surg. 2005;62(2):262-72.

15. Narula VK, Watson WC, Davis SS, Hinshaw K, Needleman BJ, Mikami DJ, Hazey JW, Winston JH, Muscarella P, Rubin M, et al. A computerized analysis of robotic versus laparoscopic task performance. Surg Endosc. 2007;21(12): 2258-61.

16. Chandra V, Nehra D, Parent R, Woo R, Reyes R, Hernandez-Boussard T, Dutta $\mathrm{S}$. A comparison of laparoscopic and robotic assisted suturing performance by experts and novices. Surgery. 2010;147(6):830-9.

17. Kernstine KH, DeArmond DT, Shamoun DM, Campos JH. The first series of completely robotic esophagectomies with three-field lymphadenectomy: initial experience. Surg Endosc. 2007;21(12):2285-92.

18. Puntambekar S, Kenawadekar R, Kumar S, Joshi S, Agarwal G, Reddy S, Mallik J. Robotic transthoracic esophagectomy. BMC Surg. 2015:15:47.

19. Sarkaria IS, Rizk NP, Finley DJ, Bains MS, Adusumilli PS, Huang J, Rusch WW. Combined thoracoscopic and laparoscopic robotic-assisted minimally invasive esophagectomy using a four-arm platform: experience, technique and cautions during early procedure development. Eur J Cardiothorac Surg. 2013;43(5):e107-15.

20. de la Fuente SG, Weber J, Hoffe SE, Shridhar R, Karl R, Meredith KL. Initial experience from a large referral center with robotic-assisted Ivor Lewis esophagogastrectomy for oncologic purposes. Surg Endosc. 2013;27(9): 3339-47.

21. Cerfolio RJ, Wei B, Hawn MT, Minnich DJ. Robotic Esophagectomy for Cancer: early results and lessons learned. Semin Thorac Cardiovasc Surg. 2016;28(1):160-9.

22. Park SY, Kim DJ, Yu WS, Jung HS. Robot-assisted thoracoscopic esophagectomy with extensive mediastinal lymphadenectomy: experience with 114 consecutive patients with intrathoracic esophageal cancer. Dis Esophagus. 2016;29(4):326-32. 
23. van der Sluis PC, Ruurda JP, Verhage RJ, van der Horst S, Haverkamp L, Siersema PD, Borel Rinkes IH, Ten Kate FJ, van Hillegersberg R. Oncologic long-term results of robot-assisted minimally invasive Thoraco-laparoscopic Esophagectomy with two-field lymphadenectomy for esophageal Cancer. Ann Surg Oncol. 2015;22(Suppl 3):S1350-6.

24. Weksler B, Sharma P, Moudgill N, Chojnacki KA, Rosato EL. Robot-assisted minimally invasive esophagectomy is equivalent to thoracoscopic minimally invasive esophagectomy. Dis Esophagus. 2012;25(5):403-9.

25. Park S, Hwang Y, Lee HJ, Park IK, Kim YT, Kang CH. Comparison of robotassisted esophagectomy and thoracoscopic esophagectomy in esophageal squamous cell carcinoma. J Thorac Dis. 2016;8(10):2853-61.

26. Chao YK, Hsieh MJ, Liu YH, Liu HP. Lymph node evaluation in robot-assisted versus video-assisted Thoracoscopic Esophagectomy for esophageal squamous cell carcinoma: a propensity-matched analysis. World J Surg. 2018:42(2):590-8.

27. Deng HY, Huang WX, Li G, Li SX, Luo J, Alai G, Wang Y, Liu LX, Lin YD. Comparison of short-term outcomes between robot-assisted minimally invasive esophagectomy and video-assisted minimally invasive esophagectomy in treating middle thoracic esophageal cancer. Dis Esophagus. 2018; https://doi.org/10.1093/dote/doy012.

28. Suda K, Ishida Y, Kawamura Y, Inaba K, Kanaya S, Teramukai S, Satoh S, Uyama I. Robot-assisted thoracoscopic lymphadenectomy along the left recurrent laryngeal nerve for esophageal squamous cell carcinoma in the prone position: technical report and short-term outcomes. World I Surg. 2012;36(7):1608-16.

29. Kim DJ, Park SY, Lee S, Kim HI, Hyung WJ. Feasibility of a robot-assisted thoracoscopic lymphadenectomy along the recurrent laryngeal nerves in radical esophagectomy for esophageal squamous carcinoma. Surg Endosc. 2014;28(6):1866-73.

30. van der Sluis PC, Ruurda JP, van der Horst S, Verhage RJ, Besselink MG, Prins MJ, Haverkamp L, Schippers C, Rinkes IH, Joore HC, et al. Robot-assisted minimally invasive thoraco-laparoscopic esophagectomy versus open transthoracic esophagectomy for resectable esophageal cancer, a randomized controlled trial (ROBOT trial). Trials. 2012;13:230.

\section{Ready to submit your research? Choose BMC and benefit from:}

- fast, convenient online submission

- thorough peer review by experienced researchers in your field

- rapid publication on acceptance

- support for research data, including large and complex data types

- gold Open Access which fosters wider collaboration and increased citations

- maximum visibility for your research: over $100 \mathrm{M}$ website views per year

At BMC, research is always in progress.

Learn more biomedcentral.com/submissions 